\title{
Design (tele-)audiovisual: os gestos de montagem em Black Mirror
}

\author{
Milena Szafir ${ }^{1}$
}

\begin{abstract}
O que me diz respeito hoje não é a realidade, mas, num sentido mais literal, a [montagem da] imagem: [...vista] tanto como resultado quanto como catalisador de uma serie de intricados processos.

(Ginzburg 2014, 63)
\end{abstract}

Esclareço que o presente ensaio possui um corpus teorico extremamente heterogêneo - uma polifonia de vozes tangenciais inter-relacionadas -, que se projetou atraves de nossa busca por decifrarmos a importância da montagem na temática constituinte às estéticas junto a série Black Mirror. Para analisarmos tais gestos, portanto, foi necessário adentrarmos em dois pontos cruciais: (1.) como o workflow do audiovisual - o processo de montagem da imagem em movimento - transformou-se em lógicas projetuais típicas do design nos últimos vinte anos e (2.) que o espetaculo, hoje telemático, e um coquetel de influências metodologicas, que se dá ubíqua e pervasivamente sob a alegoria da vigilância-controle (a interface faz uma pergunta na qual ja nos sugere uma resposta).

Para tanto, a presente escrita organiza-se em três partes: (a) aquilo que é comum em todas as séries de televisão; (b) pedagogia na escolha da série sob análise - ou, por uma filosofia do atual tele-audiovisual e (c) gestos de montagem quando o cinema se torna design.

Dessa maneira, antes de iniciarmos as análises sobre algumas das gestualidades de montagem nos episódios eleitos, permitam-me tratar criticamente sobre as imagens em movimento (e os sons a essas atrelados) que se repetem, sem cessar, ao iniciarmos todos os independentes episódios de Black Mirror (2011-) - série produzida pelo grupo Endemol Shine (responsável pela cadeia de reality shows como o antigo Big Brother e o atual Master Chef, entre outros). Originalmente exibida no canal

\footnotetext{
${ }^{1}$ Instituto de Cultura e Arte, Projet'ares Audiovisuais/ \#ir! [Intervalos \& Ritmos/ Zootropo-CNPq, 60455-760, Universidade Federal do Ceará, CEP 60440900 Fortaleza, Ceará, Brasil.
} 
público britânico e desde 2016 sob tutela do Netflix (“\$40m”; Plunkett 2016), a série possui, até o presente momento, dezenove episódios ${ }^{2}$.

\section{O que há em comum em todas as séries de televisão?}

Trata-se de uma realização audiovisual de curtíssima duração que se encontra presente em todas as séries de televisão. Ao mergulharmos em Black Mirror, nos demos conta da potência reflexiva particular de sua vinheta de abertura. Se perguntarmos a qualquer espectador qual o significado do título da série - Espelho Negro -, as respostas serão diversas mas todas, de alguma maneira, objetivas no intuito da compreensão tecnológica ao nosso redor: "Assistir ao episodio por uma dessas plataformas [Netflix, etc.] sugere tambem uma pequena quebra da quarta parede, uma brincadeira com o proprio meio [dispositivo] na qual o episodio esta sendo assistido."3

Convido, então, a verificarmos a força dialógica na pequenina sequência de abertura em Black Mirror, através de breve decupagem crítica da mesma.

\section{\#opening: the Black Mirror motion graphics}

Frente aos testemunhos coletados nas enquetes realizadas sobre a série (2016-2017), visamos compreender esse jogo sonoro-imagético da vinheta de abertura em Black Mirror como um convite reflexivo não calcado por um viés do determinismo tecnológico, mas através de leituras filosóficas e estéticas.

Qual o diferencial da vinheta de abertura de Black Mirror? De que maneira ela nos afeta e nos induz a uma escrita crítica? Sabemos que as sequências de abertura (opening title sequence) iniciaram-se no cinema desde seus primórdios (Wangen et al. 2013), e tinham por função primeira apresentar parte dos créditos da obra (diretor, produção, título, atores, etc.). Com os passar dos anos, tornam-se mais elaboradas em alguns filmes, também no sentido de que atuam esteticamente como uma curta realização audiovisual, uma narrativa síntese, daquilo que estaria

\footnotetext{
2 A temporada 1 teve estréia no Channel 4 em 04 de dezembro de 2011 com episódios semanais (The National Anthem, Fifteen Million Merits, The Entire History of You). A temporada 2 retorna a série em 11 de fevereiro de 2013, ainda no canal púbico britânico, inicialmente com episodios semanais - Be Right Back, White Bear, The Waldo's Moment; em 16/12/2014 há o acréscimo de um quarto episódio, White Christmas. A terceira temporada é lançada em 21 de outubro de 2016, então com produção-exibição Netflix e contendo já seis episódios (Nosedive, Playtest, Shut Up and Dance, San Junipero, Men Against Fire e Hated in The Nation). Mais de um ano depois, quase na virada do ano de 2017, em 29 de dezembro, a quarta - atualmente ultima - temporada é lançada no Netflix com mais seis episodios (USS Callister, Arkangel, Crocodile, Hang the DJ, Metalhead e Black Museum).

${ }^{3}$ Testemunho de aluno durante a disciplina "Estetica e Historia da Arte III: Cibercultura" (ministrada de agosto a outubro de 2017 pela autora do presente ensaio).
} 
(estará) por vir. Encontramos, nesse percurso histórico, dois pioneiros: Saul Bass - o designer norte-americano que guia importância a essas sinédoques construídas através da comunhão de elementos tipográficos e animação (Robinson 2000; Bellantfoni and Woolman 2004, Manovich 2007; Krasner 2008; Ràfols and Colomer 2010; Braha and Byrne 2011; Betancourt 2013) - e Pablo Ferro, que jogou com sobreposições entre a instituição artística e o comércio publicitário (Manovich 2013). Com o advento da televisão, se dão novas formas a essa arte-design, que passa a operar entre os intervalos de programas (notícias, série, novela, etc.), quando então possui outro tempo - que se repetirá entre capítulos, episódios ou blocos - e, muitas vezes, outras características projetuais às imagens em movimento.

No caso de Black Mirror, o motion graphics introdutório - episódio a episódio - apresenta-se como uma abstração das situações que serão encontradas ao longo de todas as narrativas. Diferentemente de outras séries em órbita nessa segunda década do século XXI (como The Affair ou a brasileira 3\%, entre outras), a vinheta de abertura em Black Mirror possui um layout minimalista - entre cores, elementos gráficos básicos, tipografia e efeitos visuais -, no qual não há cenários tampouco créditos completos, somente transições através das condensadas imagens e um repertório de sonoplastias (ao invés de uma trilha sonora com músicatema, como é comum a essas realizações).

A potencialidade nesse motion graphics, de apenas $^{4}$ quinze segundos, está em refletirmos sobre as questões mais profundas - e aterrorizantes (Burke 1998) - do espelho negro que, como fio-condutor, estão inseridas episódio a episódio, independentes entre si. A vinheta nos possibilita, portanto, uma introdução altamente reflexiva ao seu eixo temático, às lógicas nesse modelo televisivo de estrutura seriada.

Como a abertura em Black Mirror trabalha esse convite à reflexão? Inicia-se sonoramente em tela preta. Que jogo sonoro é esse? Fechemos os olhos. À primeira escuta, auferem-se frequências relacionadas com batimentos cardíacos e, ao longo dos quinze segundos, tal sonoridade pode ser dividida em quatro partes: (1.) áudios característicos do processamento de dados nos primórdios da computação ${ }^{5}$, (2.) sonoridade

\footnotetext{
${ }^{4}$ Lembramos que no processo de realização dos motion graphics impera a lógica do keyframe. Sem a compreensão desse princípio “do fazer”, nenhuma animação é possível. Por animação compreendemos o frame-to-frame em movimento. Ou seja, imagemmontagem onde, ainda que contenha os princípios audiovisuais e do design gráfico como base referencial, o motion graphics trata-se de uma lógica advinda da animação: quadroa-quadro deve ser pensado, elaborado. No "apenas", significa que uma vinheta de 15 segundos é o jogo de quatrocentos e cincoenta imagens-montagem (trata-se, portanto, de composição e encadeamento entre 450 frames com base no formato videográfico de 30 quadros por segundo).

${ }^{5}$ Através de uma arqueologia desses dispositivos para processamento de dados, os áudios nos remetem desde os cartões perfurados às fitas K7, por exemplo. Alguns dirão que não se trata de uma "arqueologia" - como nomenclatura -, no sentido de que a minha geração
} 
de carregamento -loading - nas conexões telemáticas na virada do último século $^{6}$, (3.) ruído da quebra de vidro e (4.) som-ambiência típica de suspense (Opolski 2017). Esse jogo sonoplástico, entre os bits sonoros aliados ao som da quebra espectral, finalizado por um efeito de eco em uma caixa fechada, remete-nos à filosofia flusseriana e ao romance de Lewis Carroll. Ainda que o espelho pareça uma janela que nos transportará a um outro mundo, antes ele é uma superfície prata (Szafir 2010) geradora de uma cena. Se o espelho reflete uma imagem e se toda imagem é mágica, "seu observador tende a projetar essa magia sobre o mundo" (Flusser 2002). Quando, inicialmente, o som remete a um carregamento binário digital - a uma lógica de transmissão/ conexão -, configura-se como um convite reflexivo sobre aquilo que está sendo elaborado, os programas, modelo ritualizado por tal magia projetada: "[o] fascinio magico que emana das imagens tecnicas e palpavel a todo instante em nosso entorno. [...] vivenciamos, conhecemos, valorizamos e agimos cada vez mais em func ao de tais imagens." (Flusser 2002)

Tratemos, agora, de assistirmos (sem o som) a essa construção audiovisual implícita na série televisiva Black Mirror. No horizonte de um fundo preto, centralmente, surge em branco uma linha anelar. Repentinamente ela cresce, gerando uma animação com pequeninos fragmentos brancos. Esses giram em círculo ao longo da linha anelar, então imaginária. Reconhecemos tal imagem como um símbolo computacional de loading (carregamento). Centralmente posicionado no quadro (tela), a partir de 2", um dos fragmentos geradores do conjunto anelar inicia um morph (deformação/ transição animada), transformando-se em um triângulo equilátero de arestas arredondadas, tendo sua base centralizada superiormente, e dando surgimento a outros elementos gráficos básicos horizontalmente ao redor, também em branco. Inicia-se um jogo de transição animada - em que aparecem e desaparecem diferentes elementos gráficos retangulares, triangulares e circulares numa linha horizontal imaginária centralizada em relação ao quadro (tela), nessa perspectiva em 2D. Sempre através de um efeito mirror espelhamento imagético típico das mesas de edição linear, que se estende hoje como opção nos softwares (programas) em utilização para montagem audiovisual -, onde os elementos gráficos vão sendo jogados horizontalmente desde o ponto central a certa extremidade visual sem preencher, no entanto, completamente o quadro. Nesse percurso de animação automatizada - efeito possível entre uma programação de keyframes automáticos e ajustes manuais em um software como o After Effects, por exemplo -, as letras que compõem o título da série começam a surgir (ainda através de um efeito de espelhamento) numa tipografia sem serifa de cor branca. Surgem brancas e com suas arestas

vivenciou a fita cassete em computadores pessoais, enquanto e a geração de meus pais vivenciara os maquinários com cartões perfurados...

${ }^{6}$ Conexão via discagem telefônica (algo, lembremos, que existia há pouco menos de vinte anos). 
arredondadas (como os elementos gráficos anteriores) mas com um sombreamento azul-futuro - ou deveríamos dizer, um azul-especular? Atentemos que se trata de um branco levemente embaçado. Aos 6", forma-se o título em si, a tipografia inicia o aumento de tamanho da fonte e, consequentemente, de seu kerning - cresce, portanto, horizontal e verticalmente; proporcional à centralidade em que se encontra nessa imagem-montagem, como se estivesse a se aproximar do espectador (zoom in). A tipografia, letra-por-letra, começa a tremer e, aparentemente ao tentar se desembaçar, desloca-se em três partes: o sombreamento desaparece, gerando uma imagem de quebra - como duas rachaduras na tela -, dois rasgos diagonais e em queda ${ }^{7}$ são efetuados no título (um sobre as letras A, C e K - de Black - e o outro sobre as letras M, I e R - de Mirror). As letras começam a piscar entre o branco e o azul-especular. Aos 11", elas começam a desaparecer (em um efeito de transição fade out) e, como fantasmas, somem, perpetuando a tela de fundo preto.

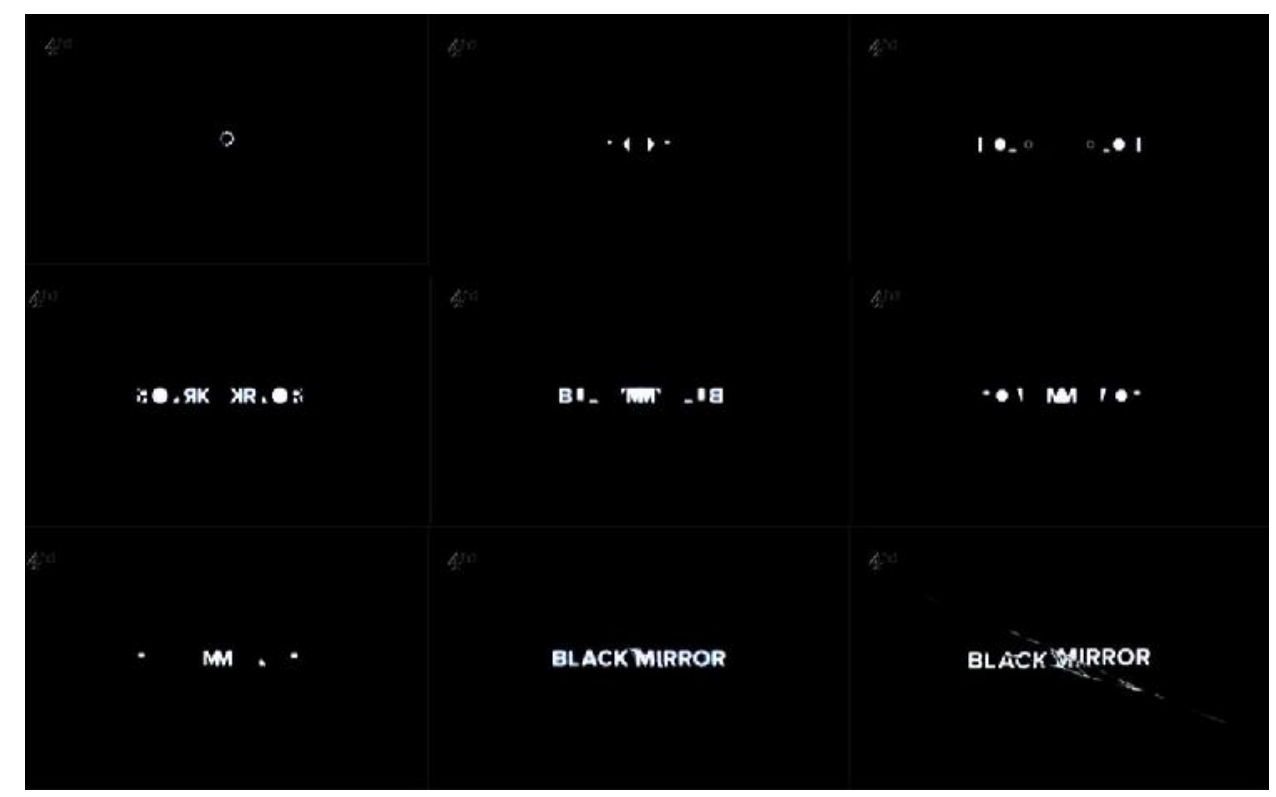

Figura 1: Fotogrmas da vinheta de abertura de Black Mirror. 2011 (c) Respect Copyright.

Se na vinheta de Black Mirror o som remete a Flusser, então a imagem remete a novas historiografias da arte. A junção dessa trilha sonora sonoplástica e do jogo de imagens em movimento confere determinado recurso estilistico que transcodifica sensações de desconforto e apreensao - como um prazer estético proporcionado pelo sublime -, emoções comumente exploradas nos diferentes episódios da série. Esse rasgar-se final na tipografia título aufere à vinheta um valor de

\footnotetext{
7 As linhas pretas diagonais - geradoras do efeito de "rasgos" - possuem seus vértices inferiores que se encontram não centralmente, mas à direita logo abaixo do título entre as letras O e R de Mirror.
} 
incisão na imagem, como um claro convite ao que se seguirá a partir de então em cada episódio sob o espelho negro, ou sobre a caixa preta:

os contornos de uma rede - estranha rede opaca cujas malhas seriam feitas apenas de espelhos. É um dispositivo de encerramento, extensível como pode ser uma rede, é verdade, mas tão fechado quanto uma caixa: a caixa da representação em cuja parede todo sujeito esbarrará como no reflexo de si mesmo. Ei-lo aqui, portanto, o sujeito do saber: ele é especulativo e especular ao mesmo tempo, e no recobrimento do especular sobre o especulativo - da autocaptação imaginária sobre a reflexão intelectual - jaz precisamente o caráter mágico da caixa, esse caráter de fechamento resolutivo, de sutura autosatisfatória. Como então sair do círculo mágico, da caixa de espelhos, quando esse círculo define nossos próprios limites de sujeitos conhecedores? (Didi-Huberman 2013, 185)

Podemos compreender tal efeito-síntese - a imagem-som da vinheta de abertura da série - como uma "rasgadura". Esse termo é utilizado por Didi-Huberman (2013) para analisar as imagens ao longo da história da arte. Proponho um encontro entre esse termo do filósofo e historiador francês ${ }^{8}$ e a escrita original para a análise de imagens técnicas - conforme proposta pelo filósofo tcheco exilado no Brasil, Vilém Flusser (2002).

Ao rachar ao meio o título da série - induzindo-nos à imagem de quebra do espelho - parte-se as noções da páthos e do logos, convidandonos a tocá-las em seus valores virtuais (potenciais) naquilo que costumamos apreender sob o termo audiovisual. A esfera das imagens e dos sons não rejeita a da lógica - pelo contrário, o áudio-visual encontrase também nesse jogo do mundo lógico e brinca com ele. Nas engrenagens desse sistema - o mecanismo do jogo - é onde obtemos sua potência, uma tal "eficácia 'sombria' que, por assim dizer, escava o visível [...] e fere o legível” (Didi-Huberman 2013, 187). Através da imaginação, pode-se não apenas elaborar, mas decifrar imagens e, ainda que pareça "demasiadamente complicado para ser penetrado" (Flusser 2002, 15), devemos adentrar a compreensão do "processo codificador que se passa no interior da caixa preta." (idem).

Em quinze segundos de uma aparentemente simples vinheta de abertura, encontra-se a síntese temática de Black Mirror: uma reunificação da cultura ocidental. Ao reintroduzir gestos característicos de nossa vida cotidiana, mesclados às gestualidades imagináveis em textos científicos herméticos, a série visa tornar "visível a magia subliminar que se escondia nos textos baratos" (Flusser 2002, 17). Ou seja, ao invés de serem meras falsificações, feias e ruins que visam eternizar-se como ato em ritual princípio a uma "sociedade em massa amorfa" -, os jogos sonoroimagéticos presentes em Black Mirror parecem servir historicamente para

\footnotetext{
${ }^{8}$ Bastante em voga no Brasil ao longo dessa primeira década do século XXI.
} 
"constituir denominador comum entre conhecimento científico, experiência artística e vivência política de todos os dias.” (Flusser 2002, 18)

Através do paradigma debordiano da transmissão televisiva sinais imagéticos e sonoros com os quais somos (fomos) bombardeados cotidianamente de meados do século XX até início do XXI, que nos engramatizaram a memória, tornando tais narrativas gestuais nosso "patrimônio hereditario" contemporâneo - e do rompimento freudiano nessa "caixa da representação" para um saber não especular -, podemos compreender a potência da vinheta de abertura de Black Mirror como metáfora do que se segue a essa, em cada independente episódio.

Portanto, apesar dos cenarios pseudo sci-fi - com aparentes avanços tecnológicos e questões distópicas -, a proposta da série é a busca por dissecar, atraves de diferentes oticas, nosso comportamento humano. A metáfora de Black Mirror não é tecnológica em sentido restrito aos objetos: diz respeito a algo mais profundo, como aquela sequência final bergmaniana de $O$ ovo da serpente (1977), que exemplifica as utilizações do "espelho negro" - uma superfície maquiada como janela - e que ocorre ainda hoje nas biopolíticas, através de amostras cibernéticas em nossos aparelhos "manuais". Ou seja, a vinheta de abertura convida não apenas a adentrar episódio a episódio, mas a dialogarmos reflexivamente sobre o mundo ao nosso redor.

\section{\#tele-audiovisualidade}

O ato de "ver séries de televisão" faz parte dos momentos de descontração e lazer entre os seres urbanos. No entanto, ao longo dos últimos três anos, esse ato junto à série Black Mirror fez parte de nossa experiência didática no ensino-aprendizagem das estéticas de montagem em nível universitário. O autodidatismo "cinéfilo"9 de nossos estudantes ocorre via computadores conectados em rede. Isso significa, portanto, uma cinefilia através de repositórios on demand, como os mensalmente pagos (Netflix, por exemplo) ou os "gratuitos" - YouTube (da Google) e distintos compartilhamentos voluntários $p 2 p$ via Torrent. Em seu ensaio crítico sobre o cineasta que então já flertava com as estéticas da televisão, Daney (2007) recorda a causa de uma possível "pedagogia godardiana":

A grande suspeita colocada pelo Maio de 68 sobre a "sociedade do espetáculo" [de Guy Debord, 1967, ...] atinge a geração que mais havia investido nesse processo, a dos autodidatas cinéfilos, para quem a sala de cinema tomou o lugar, ao mesmo tempo, da escola e da família [...] Em 1968, para a facção mais radicalizada - a mais esquerdista - dos cineastas, uma coisa é certa: é preciso aprender a sair das salas de cinema (da

\footnotetext{
9 Utilizamos no presente ensaio a denominação “cinema” desde sua etimologia constituinte. Ou seja, também as derivações (tais como "cinéfilo" ou "cinefilia”, etc.) auferem ao todo relacionado à "imagem em movimento" com suas diferentes estéticas, tecnologias e temporalidades.
} 
cinefilia obscurantista) ou, ao menos, conectá-la a qualquer outra coisa. (Daney 2007, 107)

Guy Debord ([1967] 1994) é comumente associado a uma crítica das imagens que nos rodeiam. No entanto, para adentrarmos a essencialidade da montagem à temática em Black Mirror, guiaremos toda a análise no presente ensaio a partir de um dos primeiros aforismas no livro A Sociedade do Espetáculo: "o espetáculo não é um conjunto de imagens, mas uma relação social entre pessoas mediadas por imagens [e sons]". Ou seja, convido a compreendermos o Netflix - um dispositivo calcado nas lógicas da nuvem e nas estéticas do banco-de-dados - e a série Black Mirror desde um paradigma debordiano (a interface mediadora em rede).

Partindo desse princípio, compreende-se que "o espetáculo" para Debord tratava-se do dispositivo televisivo - a nova midia em rede à época com pote ncia dominante ao seu redor. O contexto debordiano encontrava-se na proliferac ao midiatica televisiva. O paradigma debordiano partia, portanto, da inovac ao tecnologica de seu tempo (as redes de televisao). Ou seja, a sociedade do espetáculo não aufere "simplesmente" a questões da imagem ou especificamente ao cinema ${ }^{10}$.

Muitas das imagens em seus tre s filmes da decada de 1970 aludem, conforme ja foi dito anteriormente aqui, as imagens de circuitos televisivos; o contexto debordiano e atestado junto a diversas publicac oes a respeito da inaugurac ao da televisao e sua proliferac ao midiatica - e tecnologica - ao redor do mundo. [...] "'em 1955 cerca de dois terc os dos domicilios americanos ja possuiam um aparelho de TV, e, em 1960, 90\% das reside ncias ja contavam com pelo menos um aparelho.' " Basta compreendermos a Franc a de Debord e a Europa como um todo no pos-guerra, tendo com informac ao tambem que o primeiro canal de TV foi fundado em 1936: a BBC de Londres, e na decada de 50 iniciaram-se uma gama de canais a escolha do telespectador, assim como a chegada dos primeiros televisores a cores. Ja na decada de 1970, por exemplo (e de onde fala Debord), ha uma revoluc ao tecnologica que transforma a disseminac ao da TV por cabo e satelite, consolidando-se assim o poder total do transmissor em seu conteudo. (Szafir 2009)

As redes de televisão operavam através de programação fixa: horários pré-definidos que possibilitavam o tele-espectador assistir às séries, quando então se construía certa ansiedade pelo próximo episódio que, na maioria dos casos, estaria disponível somente na semana seguinte. Hoje, no entanto, Black Mirror encontra-se em alguns menus ( a la carte):

\footnotetext{
${ }^{10}$ Como sabemos, Guy Debord dialogava com uma rede de cineastas franceses e realizou algumas obras cinematográficas às quais que, enquanto conjunto, denominou "anticinema".
} 
"TV Shows", "Sci-Fi \& Fantasy", "Trending Now", "Popular on Netflix", "Critically-acclaimed TV Shows" etc. E a $4^{\text {a }}$ quarta temporada, segunda sob a tutela do Netflix, foi lançada há alguns meses (dezembro de 2017). Tomemos em conta de que, ao longo da segunda década dos anos 2000, os aparelhos de telefonia telefone móvel - conectados à Internet e com uma variedade cada vez maior de aplicativos - transformaram-se em "controles remotos" também ${ }^{11}$. Ou seja, ao clicar no ícone do aplicativo Netflix instalado em um celular, o usuário (tele-interactant) recebe um, aparentemente, vasto menu à sua escolha. Tal area de escolha é uma interface, uma membrana ideologica nao-transparente, um nexus fertil (Galloway 2009).

Conceitualiza-se, assim, o espetaculo como a mediac ao em/ da rede,; em que onde toda a mediac ao (imagem/ interface) e derivada da somatoria do aparato tecnico (midiatico) com a linguagem (forma/conteudo) e/ em seu determinado ge nero. Ou seja, interface frequentemente e sino nimo de midia, e sempre um efeito - um efeito relacional:

pertence as (tele-)conexoes, aos sistemas de tempo e rotas logisticas [...] um jogo de espac o auto-descentralizado [...] A chave-projetual do jogo e a rede de conexoes [...] A alegoria debordiana sobre o algoritmo [...] da nova sociedade da informac ao que crescia ao redor dele nos anos 1970. Em suma, o jogo de Debord e algo como um “'xadrez conectado"'... (Galloway 2009, 143)

Diferentemente daquela geração de 1968 na França, interligada pelas centrais de transmissão áudio-visual que nos tornaram uma espécie de aldeia global (McLuhan 1967), a atual não resiste ao espetáculo. O Netflix - como um dispositivo neo-televisivo - caracteriza-se por ser uma caixa preta: uma nova despotencialização do indivíduo, um retorno às lógicas do corpo dócil e da biopolítica, um adestramento continuo e um controle permanente dos gestos na especie humana. O poder nao age somente no individual, mas na populac ao como um todo. A montagem do discurso no agora tecnológico que seguramos em nossas mãos ocorre atraves de justaposições e sobreposições do corpo-homem (disciplina) e do homem-especie-populac ao (biopoder).

Dessa maneira, Black Mirror junto ao Netflix aufere um upgrade da caracteristica benthaminiana: da disciplina desde seus primeiros anos de formac ao, o ser humano passa a ser dominado também pela biopolitica, o que significa controle intermitente, onde o "tempo real" se faz presente e o controle sobre o fluxo informacional e infinito. Daquele modelo que servia para moldar, insere-se também a medida de modular este homem,

\footnotetext{
${ }^{11}$ Uma alusão aos televisores com controle remoto, mas na conjunção dessas palavras frente ao dispositivo citado podemos auferir outros questionamentos (implícitos à série sob análise aqui, como veremos adiante).
} 
transformando-o em amostras populacionais. Ou seja, não se trata somente de instituic oes disciplinares (ou cercamentos), mas de circulac ao - questões de mobilidade: "[trata-se] de fazer os elementos de realidade funcionarem uns em relação aos outros.” (Foucault 2008, 86)

São as sociedades de controle que estão substituindo as sociedades disciplinares. "Controle" é o nome que Burroughs propõe para designar o novo monstro, e que Foucault reconhece como nosso futuro próximo. [...] o essencial não é mais uma assinatura e nem um número, mas uma cifra: a cifra é uma senha, ao passo que as sociedades disciplinares são reguladas por palavras de ordem (tanto do ponto de vista de integração quanto de resistência). A linguagem numérica do controle é feita de cifras, que marcam o acesso à informação, ou à rejeição. [...] Os indivíduos tornaram-se "dividuais", divisíveis, e as massas tornaram-se amostras, dados [data], mercados ou "bancos" [banks] É fácil fazer corresponder a cada sociedade certos tipos de máquina, não porque as máquinas sejam determinantes, mas porque elas exprimem as formas sociais capazes de lhes darem nascimento e utilizá-las. (Deleuze 2007, 222)

Portanto, tomemos em conta que os nossos estudantes não assistem a uma série "de televisão". Aquela televisão que - como dispositivo e herança da geração de Guy Debord - esteve fortemente presente em nossas sociedades pós-modernas (o doentio modernismo tardio) com uma transmissão de natureza estética distinta da atual. Os jovens da atual geração - nascidos na virada do século XX para o XXI assistem, tal como nós, bancos-de-dados (database) em rede, nos quais o Netflix caracteriza-se como um dispositivo típico da segunda década do século XXI. Ou seja, é nessa contramão estético-política daquela web 2.0 (Szafir 2017) onde se configuram as percepções de nossos alunos (que nos indicaram a série). Atento, nesse ensaio crítico sobre Black Mirror, a um foco pedagógico, portanto: compreendermos de que maneira - desde a perspectiva do paradigma debordiano - tal montagem trabalha as atuais imagens do espetáculo, fazendo com que a mediac ao tecnologica insirase em termos de afecção a um diálogo reflexivo.

Dessa maneira, a potência da montagem audiovisual em Black Mirror é trabalhada através de uma lógica metalinguística: simulação de específicas estéticas do banco-de-dados (database aesthetics). É através dessas estéticas do digital que se dá o jogo de gestos de montagem na série; uma montagem audiovisual que - da composição imagetica à mixagem de efeitos de nao-perfeic ao - parece buscar o ponto em que a imagem e o som (como meio) se torne algo sensorialmente inquietante: do encontro critico-reflexivo com a midia ao choque junto ao espectador. Lembramos, ainda, que essa foi também a proposta dos primeiros teóricos-realizadores da montagem cinematográfica nas primeiras décadas do século passado, perpetuando-se na Glitch Art junto a primeira década dos anos 2000: 
todo elemento que submete o espectador a uma ac ao sensorial ou psicologica, experimentalmente verificada e matematicamente calculada, com o proposito de nele produzir certos choques emocionais que, por sua vez, determinem em seu conjunto precisamente a possibilidade do espectador perceber o aspecto ideologico daquilo que foi exposto [...] O processo do conhecimento - "atraves do jogo vivo das paixoes" (Eisenstein [1923] 1983, 189).

\section{\#composição: outros gestos de montagem}

Ainda que a série Black Mirror possa ser interpretada como um pastiche pós-moderno em rede (Szafir 2018), há dois outros padrões estruturais a todos os episódios da série. O primeiro, sobre o qual não nos estenderemos, refere-se a uma estrutura narrativa de cunho fabularmoralizante: tal qual nas fabulas (de La Fontaine, por exemplo), as suas sequências finais desembocam na "moral da história". A exemplo, citamos dois episódios que constroem seus protagonistas como heróis de uma revolta latente - busca pela liberdade de expressão: Fifteen Million Merits (escrito por Charlie Brooker, produtor da série, em parceiria com Konnie Huq; 2011) e Nosedive (escrito por Charlie Brooker e roteirizado por Rashida Jones e Michael Schur; 2016). Fifteen Million Merits é o segundo da primeira temporada (ainda no Channel 4, portanto) e Nosedive é o primeiro da terceira temporada (episódio inicial produzido junto ao Netflix). Enquanto nesse a protagonista sofre as consequências de seus atos (situação non sense na cultura dos likes), naquele o protagonista é engolido como parte da engrenagem do próprio sistema (situação tipicamente de um discurso contracultural cooptado pelo capitalismo televisivo). Ao fabularmente explorar o sublime junto aos espectadores, Black Mirror desempenha um duplo papel: estético - a experiência do prazer entre Aristóteles, Longino, Burke e Kant - e didático (ensinar algo sobre o entorno - "a realidade" - do espectador).

O segundo padrão é aquele que nos interessa no presente ensaio: como a série afeta diversos espectadores? A hipótese desse como parte de decupagens para compreensão da construção de sua forma imago-sonora, de Eisenstein $(1988 ; 2002)$ a Manovich (2013). Aqui apresentaremos um dos gestos de montagem em Black Mirror com foco nos recursos da imagem-montagem - composição projetual baseada em multi-layers (Szafir 2015) -, auferindo importância aos motion graphics (aplicação do design em movimento) na série, uma arte da invisível linguagem visual de nossa cultura profundamente hibridizada pela remixabilidade midiática:

a cultura moderna visual foi substancialmente transformada. Meios até então separados - live action, grafismos, fotografia estática, animação, computação gráfica tridimensional e tipografia - começaram a ser combinados de inúmeras maneiras. Ao final da década [de 1990], a imagem em movimento "pura" tornou-se uma exceção e a mídia híbrida passou a ser norma. No entanto, ao contrário das demais revoluções digitais - como o surgimento da World Wide Web ao redor da mesma 
época -, essa revolução não foi reconhecida pela mídia popular ou pelos críticos culturais. [...] enquanto os resultados dessas transformações se tornaram já bastante visíveis desde 1998, até o presente momento em que aqui escrevo (início de 2006), não estou ciente de um único artigo teórico em que isso seja debatido. (Manovich 2007, 68; tradução minha)

Será a partir desse complexo design em movimento - o que Manovich denominara "Velvet Revolution"12 (2007) ou "How Cinema Became Design" (2008; 2013) - que argumentarei ser a chave para (onde ou na qual se revela) a força daquilo que nos afeta nessa série. Nesse percurso, seremos auxiliados por um viés filosófico sobre como uma obra nos afeta esteticamente junto ao viés analítico da montagem audiovisual digital para além dos estudos filmográficos, tendo em vista também de que alguns autores como Krasner (2008), Manovich (2007; 2013), entre outros, passariam a nos convidar a compreender o sistema híbrido dessa linguagem das atuais imagens em movimento.

Ao tratar dos afectos, Spinoza (2008) trabalhara o termo em latim - anima pathema -, que significa a potência-paixão para agir (aquilo que causa afecção na alma). Como o encontro com Black Mirror nos afeta? A teoria das artes (e suas práticas desde o Renascimento) foi profundamente alterada na Aufklarung (século XVIII) através da virada filosófica sobre estética desde Burke (1998), Hume (2002) e Kant (2002). Passa-se então da teoria da mímesis a uma inicial teoria da recepção. Em sequência às viradas no modus operandi das artes (suas teorias, historiografias e práticas), no início do século XX Aby Warburg propôs o projeto visual de montagem (work in progress) Atlas de Imagens (Bilderatlas) Mnemosyne. A chave para compreendermos esse jogo imagético através dos intervalos é o conceito warburguiano Pathosformeln (Szafir 2014) -, termo que mescla o grego (Pathos ${ }^{13}$ ) e ao alemão (Formeln) - conceito que, no presente ensaio, nos é de interesse, pois foi através desse método que se elegeramos as gestualidades das imagensmontagens em Black Mirror. Ou seja, uma tentativa de compreendermos os gestos de montagem que trabalham aquilo que nos afeta na contemporaneidade das transmissões audiovisuais: como essa série opera, episódio a episódio, tal qual prancha a prancha de Warburg (Szafir 2018).

Warburg compreendeu que existe uma forma gestual-visual nas obras de arte que se perpetua no imaginário da paixão (àquilo aquilo pelo que somos afetados). As fórmulas da paixão - gestos emotivos arquetípicos, que se repetem nas visualidades da arte ocidental transcodificam o conteúdo em formas como "engramas de uma experiência apaixonada [que] sobrevivem como patrimônio hereditário

\footnotetext{
$12 \mathrm{O}$ substantivo velvet (veludo), quando colocado como adjetivo, é associado a smooth (suave) ou soft (mole, flexível, macio).

${ }^{13}$ Pathema em latim, como lemos em Baruch Spinoza (2008).
} 
gravado na memória" (Warburg apud Szafir 2014). Warburg dá sequência, portanto, ao que Burke (1998) estabelece como estética do sublime, a operação da mais potente paixão, gestualidades da afecção:

Qualquer que seja o encaixe entre as ideias de dor e perigo, digamos, nao importa quao terriveis sejam ou ainda quao familiares [reconhecidos] se apresentem como objetos terriveis ou que analogamente opere como terror, essa e a fonte do sublime; ou seja, e a produc ao da mais potente emoc ao cuja mente e capaz de sentir. (Burke apud Szafir 2015, 38)

Tomemos em conta, ainda, de que Black Mirror adentra uma póscibercultura através de jogos sonoro-imagéticos calcados nas Pathosformeln da cinematografia em ficção científica. A série não é futurística, seu visual design trabalha a atualidade dentre nossos mais íntimos e sublimes pesadelos:

The forms live on, one remembers them, because the basic questions of orientation on remain the same for humankind in all ages. In spiritual distress and in the struggle for level-headedness - 'Sophrosyne' "Sophrosyne" - it is 'Mnemosyne'"Mnemosyne", the European memory of images, that provides older topoi. The main feature of artistic objectifications, which borrow from the 'mnemonic "mnemonic energies' energies" of collective recollection, is neither the limited, explicit, and instrumentalizing reference to the past nor a concept of memory, but rather those characteristics which indicate how fear as the decisive driving force can be overcome through contemplation. Works of art are products of these expressive energies; to Warburg they are retained as engrams in a collective memory, products of a process of balancing on on the model of the present, which also hold "'energies"' for the future and are thus never done with historically. (Diers et al. 1995, 72)

Quando aplicamos o método warburguiano à série Black Mirror identificamos, à em princípio, três gestos de montagem que se repetem em diferentes episódios como subjetividade corporal das protagonistas auferindo modelos de afecção junto ao espectador: (1.) Glitch-alike; (2.) Realidade Aumentada e (3.) Mask-eyes (Szafir 2018b). A exemplo, em Men Against Fire (2016) - quinto episódio da terceira temporada podemos encontrar essas três formas compositivas em 11 sequências ao longo de 57 minutos.

\section{\#gestos1}

O argumento em Men Against Fire consiste em uma intervenção higienista por parte de um exército estrangeiro em localidade geográfica não identificada onde, segundo cientistas, a população do local desenvolvera uma mutac ao genetica contagiosa à para a humanidade, fazendo também com que os infectados se tornem-se criaturas violentas e possuam 
tende ncia para comportamento criminoso, etc. A fim de proteger a populac ao humana ainda saudavel, forc as militares mobilizadas operam na caça e no combate à proliferac ao desses individuos contaminados - denominados "baratas". Dessa maneira, a trama é desenvolvida no conflito entre o alien e a sobrevive ncia dos seres humanos ainda "puros" sob proteção militar.

O olhar designado - filtros tecnológicos aplicados aos olhos - é um dos gestos de montagem que permeiam diferentes episódios de Black Mirror, a partir do qual somos convidados às imagens subjetivas de suas protagonistas. Tendo como único autor Charlie Brooker (produtor original da série), o episódio Men Against Fire - ainda sob a coordenação de design de Joel Collins (Szafir 2017) - segue a jogar com essa função do olhar: entre o dispositivo de gravação/ visualização da memória e as falhas digitais.

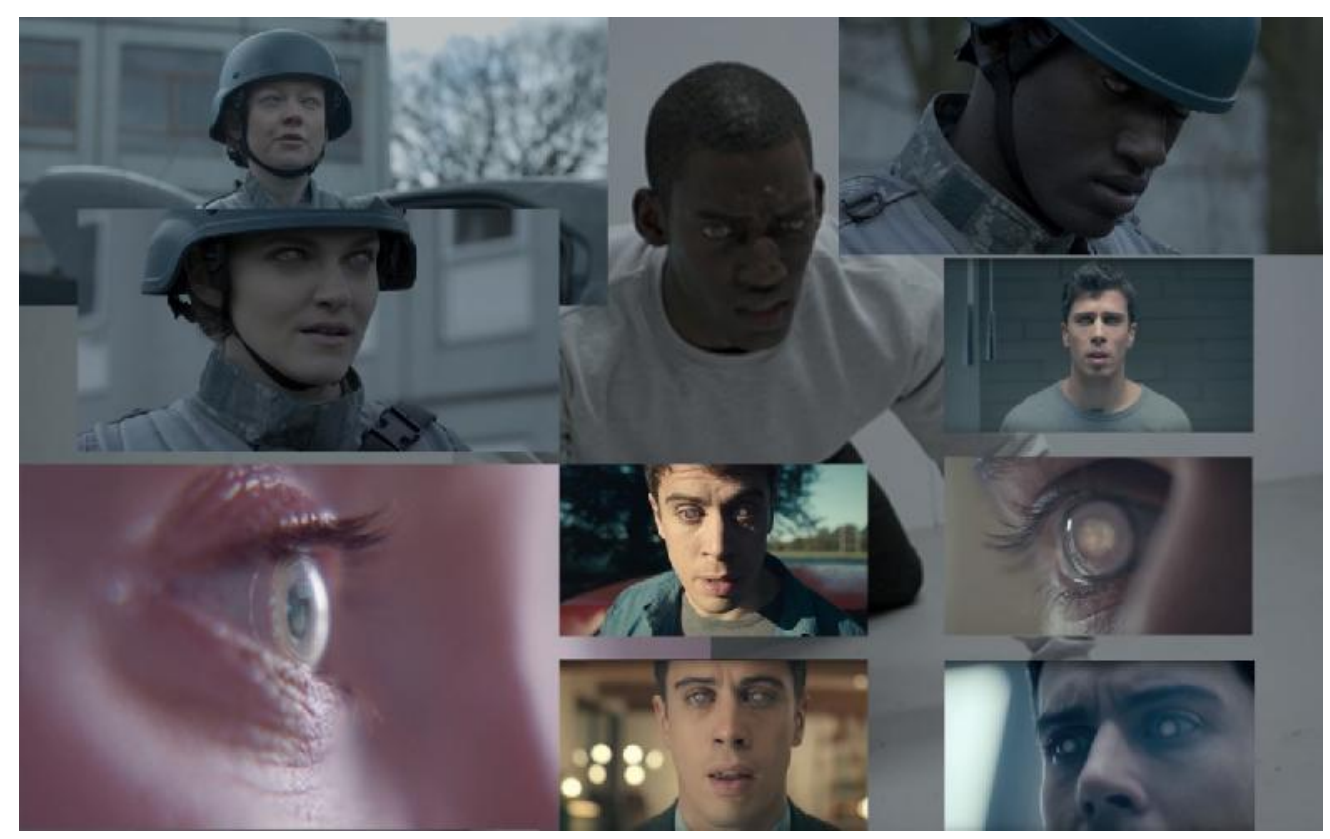

Figura 2: Fotogramas de três episódios da série Black Mirror: "The Entire History of You" (1.03); "Men Gainst Fire" (3.05); e "Nosedive" (3.01). 2011-2016. (c) Respect Copyright.

A composição no/ do olhar, através da manipulação do globo ocular como um filtro de efeito autômato, é uma gestualidade de montagem visual característica tanto da cinematografia internacional do ponto de encontro de captação energética (The Dark Crystal 1982 ${ }^{14}$ ) à verificação da existência humana (em contrapartida aos aliens, androides, como em Blade Runner 198215) - quanto do imaginário criado na

\footnotetext{
${ }^{14}$ No presente ensaio não trataremos do olhar como gestualidade de zoombies.

${ }_{15}$ Sci-fi distóptico baseado na obra de Phillip K. Dick que, cinematograficamente, implementa a teoria de Alan Turing.
} 
literatura fantástica (O homem da Areia 181516). Black Mirror trabalha também na lógica de pós-impressões digitais: as leituras de íris como meio da catalogação individual das identidades (Minority Report 2002).

Galton [1888] propusera um método de identificação [...] no que se referia tanto à coleta de dados como à sua classificação. $\mathrm{O}$ método baseava-se, como se sabe, nas impressões digitais. [...] A análise científica das impressões digitais iniciara-se desde 1823. (Ginzburg 1989, 174)

Esse gesto de montagem - o denominemos aqui de "olhar designado" - trabalha, a nível estrutural narrativo, a aplicação de um implante ao longo de diferentes episódios: dispositivo que, extraidentificação, também captura e grava as imagens vivenciadas pelas personagens (memorificação cotidiana). A nível compositivo (de montagem), torna-se também uma visualização - na lógica da realidade aumentada - por parte das personagens com relação a um amplo espectro da database informacional ao redor. O diferencial no episódio Men Against Fire encontra-se na capacidade de tal dispositivo implantado que passa a maquiar os quatro sentidos - tátil, olfativo, visual e de escuta. Inibe-se nos soldados, dessa maneira, sentimentos de empatia ou culpa. O diálogo na sequência entre o médico-psicólogo do exército e o soldado-protagonista trabalha tal filtro autômato sob a nomenclatura de mask. Em termos tecnológicos, máscara é o nome dado à função técnica compositiva junto ao software After Effects da Adobe para aplicação dos motion graphics e efeitos visuais que permeiam, numa iconologia dos intervalos, grande parte dos episódios. É dessa maneira - entre a gestualidade compositiva da montagem e a explicitação verbal no diálogo - que se insere nesse episódio de Black Mirror um jogo de metalinguagem - "a máscara do olhar": o filtro ao Outro, ao "inesperado", ao "estrangeiro".

Sob direção de Jakob Verbruggen - montagem de Ben Lester, direção artística e efeitos visuais de Shaun Fenn, Richard Field, Daniel May e Robyn Paiba -, essa particularidade temática como argumento em Engenharia Reversa, título no Brasil de Men Against Fire, remete-nos ao texto Das Unheimliche, de Freud ([1919] 2001). O psicanalista, ao analisar os aspectos do consciente e do inconsciente no conto $O$ Homem de Areia (Der Sandmann, 1816), de E.T.A. Hoffmann, dialoga com a máscara de Men Against Fire, em vista de que ambas as obras possuem dispositivos tecnológicos como extensão do homem - cada qual a seu tempo - em um nível codificado na representação da realidade:

The German word unheimlich is obviously the opposite of heimlich, heimisch, meaning "familiar", "native", "belonging to the home"; and we are tempted to conclude that what is "uncanny" is frightening precisely because it is not [grifo meu] known and familiar [...] the uncanny would always be that in which one does not know where one is, as it were. The

${ }^{16}$ Onde Neste, a questão do olhar já designava tal diferenciação entre humano e nãohumano atrelada às tecnologias das cientificidades ópticas "aterrorizantes". 
better orientated in his environment a person is, the less readily will he get the impression of something uncanny in regard to the objects and events in it. [...] Indeed, we get the impression that many languages are without a word for this particular variety of what is fearful. [... In Greek:] Xenos strange, foreign. ENGLISH: [...] a repulsive fellow. FRENCH: [...] Inquietant, sinistre [...] SPANISH: [...] Sospechoso, de mal aguero, lugubre, siniestro. The Italian and the Portuguese seem to content themselves with words which we should describe as circumlocutions. In Arabic and Hebrew "uncanny" means the same as "daemonic", "gruesome". (Freud 2004, 76-77)

A potência da série se dá nessa constância da composição visual como gestos de montagem. Processualmente, em como a imagem em movimento (cinema) se tornou design - para utilizarmos o título original (no rascunho) a um dos capítulos em Software Takes Command (Manovich 2013). Ou seja, tais trucagens pós-Meliés - ao se utilizarem da arte dos motion graphics em comunhão ao live action - criam uma linguagem visual híbrida aos gestos de montagem nas estéticas do digital.

\section{\#gestos2}

Em Men Against Fire, temos a imagem-montagem - live action com sobreposições entre efeitos visuais e motion graphics - trabalhando de diversas maneiras desde o olho embaçado (ausência da íris, conforme vemos na Figura 2, que remete as personagens a quase-cyborgs) às alusões das tecnologias em realidade aumentada. Como se revela o primeiro incômodo no olhar designado do protagonista e o argumento do Outro ao espectador? Ao decuparmos Men Against Fire, encontramos dois gestos de montagem - sintomas gestuais típicos em Black Mirror ("realidade aumentada" e glitch-alike) - em uma das principais sequências (aos dezoito minutos do episódio). O gesto de montagem glitch-alike aufere uma falha de transmissão tipicamente digital (Moradi 2004), sugerindo, portanto, um defeito tecnológico à visão subjetiva do protagonista.

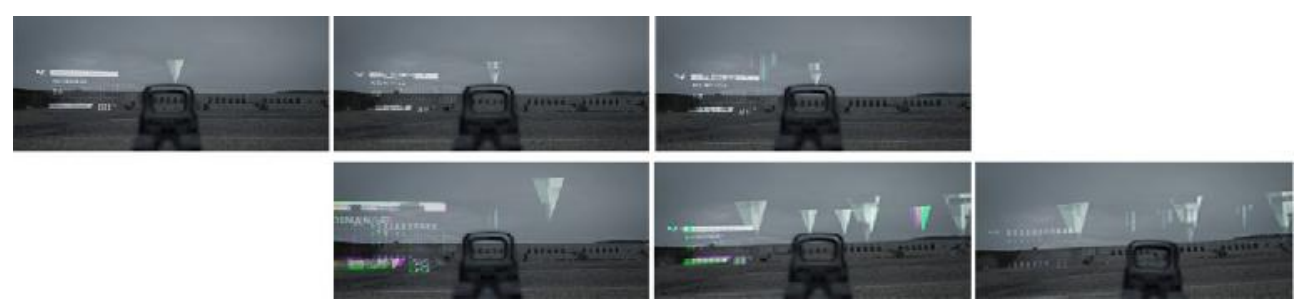

Figura 3: Planificação de 1seg. 15fr (alguns fotogramas na sequência). ㄷ Respect Copyright 
A sequência planificada acima remete o espectador geracional a um jogo virtual em primeira pessoa (FPG - First Person Game). No jogo da montagem - justaposição entre planos e contraplanos das personagens e suas visões subjetivas - encontra-se a dramaturgia da forma que posiciona, localiza e conflitua o espectador no espaço ao longo da estrutura narrativa. Com duração de apenas um segundo e quinze frames (a partir de uma decupagem realizada no software Adobe Premiere), a composição visual via multicamadas, aliada ao live action - mira do rifle em primeiro plano com um plano geral ao fundo -, opera no desfacelamento da forma triangular única, enquanto reparte os demais grafismos em branco à esquerda - o conjunto em motion graphics multiplica-se em pixelizações através de cores complementares à tonalidade fotográfica original -, significando danos ao implante digital na personagem-protagonista (imagem-montagem com aplicações do sintoma glitch-alike). Tais falhas imagéticas à câmera subjetiva - que auferem à narrativa tal defeito no dispositivo implantado - são operadas diferentemente em outra sequência (a do sonho do soldado): entre efeitos de glitch-alike e um jogo imagético que remete aos flicker films de Paul Sharits.

descobri que "Cinético" era uma "expressão" que significava mais do que "montagem criativa" (a manipulação do espaço-tempo; inventividades metafórica-imagísticas) ou "câmera-sensitível" (movimentos expressivos de câmera, enquadramento, tonalidade composicional, etc). [...] Então, eu comecei a olhar para as atuais materialidades e procedimentos de minha mídia, naquilo que elas possuem de mais básico e óbvio, para a questão do "ente" em si e em como apropriar-se de seus princípios estruturais como um todo." (Sharits apud Szafir 2018b)

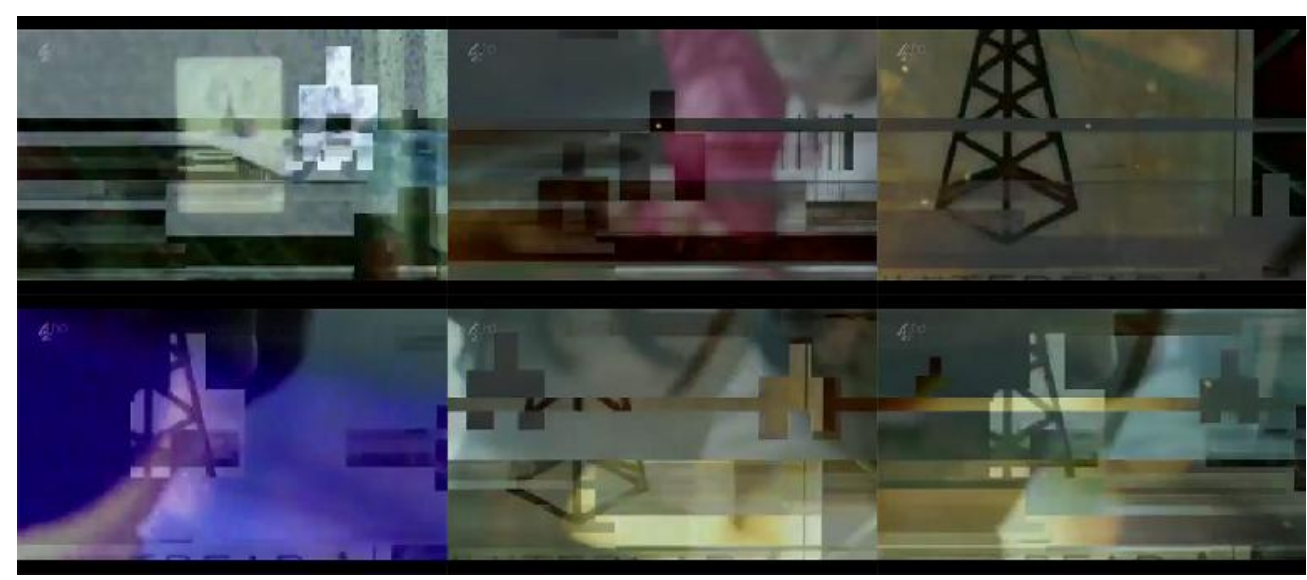

Figura 4: Seis fotogramas no episódio "White Bear” (2.02) 2013. (C Respect Copyright

White Bear (2013) já havia potentemente trabalhado os mesmos gestos de montagem glitch-alike; no entanto, operava narrativamente como flicagens da memória. Somos introduzidos ao episódio por ruídos sonoros e, então, disparos imagéticos são acrescentados. Tais imagens 
remetem, inicialmente, às experiências em videoarte ou, ainda, advindas do cinema experimental. Geradas a partir da estetica glitch, trata-se de planos (imagem-montagem) de curta duração conjugados em cortes secos, jogo que não apenas obriga o espectador a mergulhar na contempora nea realidade digital (computer-based), como o convida desde o início - a refletir sobre questões implícitas à magia em transmissão. Tal utilização de uma montagem metalinguística, que inicia o episódio, significa que ha algo a ser dito que de outra maneira nao o seria. Essas imagens que nos assolam se dão no ritmo privilegiado de uma partitura audiovisual, conforme promulgado na montagem vertical (Eisenstein 2002).

Esse conjunto de planos (Figura 4), entre distintos gestos de montagem (justaposições aliadas a composições internas), dura apenas dez segundos - velocidade de uma blitzkrieg retiniana. Nossa atenção, como espectador televisivo, é então capturada nessa curta montagem de duração típica de publicidade online nos repositórios de vídeo on demand (como ocorre no YouTube, por exemplo, mas aqui não podemos clicar em "you can skip this ad in xx seconds"). Assim iniciava-se o segundo episódio da segunda temporada da série de Charlie Brooker no Channel 4, canal estatal da televisão britânica:

Como mostrar, a uma criança que não sabe ler, 62 vezes a palavra casa sem que ela durma diante da TV? [...] Nossa busca passou a ser a de criar um formato muito atrativo. Se as crianças não aprendessem nada, ao menos iriam se divertir. Queríamos garantir audiência. Partindo da constatação óbvia de que uma criança de quatro anos é dispersa, tem dificuldades para acompanhar uma trama muito complicada ou reconhecer muitas personagens [...] e assim que se cansasse mudaria de canal, optamos por fazer isso antes dela. Criamos um formato fragmentado e ágil [...] Sempre vimos o programa como uma cachoeira de estímulos. (Meirelles 1990, 264)

Black Mirror, teoricamente, não é um programa para crianças. Mas a série joga com esse espectador contemporâneo que, quanto mais conectado está, mais infantilizado se torna. Portanto, se retornarmos àquela hipótese primeira - à lógica do duplo papel da série - podemos compreender Black Mirror como entretenimento e como um meio educativo: uma exploração reflexiva sobre nossa sociedade atual, permeada por inovações tecnológicas, tendo em vista que a ficção científica (surgida no século XIX) não estava somente ligada à ciência, mas a um novo ideal daquele período que era "a educação para todos, e portanto a comunicação das verdades" (Dufour, 2011).

Retornemos à breve decupagem (descrição de parte da sequência inicial) em White Bear e tentemos compreender como somos afetados, enquanto espectadores, por esses gestos de montagem. A edição daqueles primeiros dez segundos (Figura 4) aplica na retina do espectador um símbolo, subliminarmente trabalhado como falha nesse glitch-alike. Novo 
corte seco: um primeiro plano nos apresenta a primeira personagem, uma mulher. Segue-se para um plano de pormenor (visão subjetiva) e, após esse inicial jogo de raccord - que dura cerca de trinta segundos (expandidos temporalmente pelo ritmo na montagem), - entra outro primeiro plano (é para onde a personagem olha). Nessa nova imagem que nos é apresentada - enfoque não estático da personagem - vemos um antigo televisor (de tubo, ainda que de tela plana) que projeta um símbolo de cor branca sobre um fundo negro.

Após sermos introduzidos à primeira personagem (a mulher que descobriremos ser a protagonista), ela nos convida através de seu olhar a uma outra imagem, que dura apenas três segundos. Esses três segundos são suficientes para nova introdução ao televisor com aquele branco signo que, então, "flica". Tal símbolo configura-se em um marcador digital que, quando ativado, remete o dispositivo leitor a uma ação. Nesse caso, tais gestos de montagem nos convidam a uma noção de "flickers of memory" (Szafir 2017) em que a mulher, ao ser exposta (ao ver) o símbolo - signo da cultura digital em vigilância e controle -, é acometida por essas imagens trabalhadas como (simuladas em) estética glitch art, ou seja glitch-alike. Dá-se, dessa maneira, o iniciar desse episódio: um disparo digital de engramas da memória e, então, apresenta-se o logo-marcador. Ao longo do episódio, descobriremos que as imagens subjetivas mnemônicas da protagonista são ativadas através dessa imagem-logo do jogo estético a que fomos inicialmente introduzidos.

White Bear é um episódio construído através de uma série de citações culturais - cinematográficas e filosóficas - das décadas de 1960 e 1970. Por exemplo, a sequência na qual há um grupo de pessoas que, com seus celulares em punho - clara alusão à McLuhan ([1964] 1969) -, persegue a personagem. A cena captura a atenção da nova geração: "Grupos de pessoas a filmam. Fascinados (ou hipnotizados) para capturála em seus aparelhos celulares. Vê-la através de suas telas na palma-damão"17.

Entre a paranóia da personagem sob perseguição e a sedução daqueles que se comportam como vigias em uma espécie de jogo de punic ao nesse parque de diversões - "na serie e chamado parque de justic a. O qual todos, exceto ela, sao atores ou espectadores que pagam para ve -la, diariamente, passar por uma tortura similar a que cometeu no passado" 18 -, retornamos a Foucault (2001). Ou seja, tal qual ocorre no projeto de arquitetura panóptica:

torna-se ironicamente um pequeno teatro de aparentes virtudes e, desta maneira, se adequa perfeitamente ao conceito de Bentham: "O Panóptico é antes de tudo, uma escola de virtudes, onde personagens odiosos

17 Testemunho de aluno durante a disciplina "Estetica e Historia da Arte III: Cibercultura" (ministrada de agosto a outubro de 2017 pela autora do presente ensaio). 18 Testemunho de aluno durante a disciplina "Estetica e Historia da Arte III: Cibercultura" (ministrada de agosto a outubro de 2017 pela autora do presente ensaio). 
encenam diariamente o drama da punição. Como tal, ele deve ser aberto à visitação pública, deve ser um local de instrução, um teatro educativo para onde os pais levam em passeio os seus filhos". (Szafir [2004] 2006)

Se os vigias são regidos pelos "novos" dispositivos em conexão, ao longo de todo o episódio a montagem nos remete constantemente a outro signo mais: torres de transmissão e de recepção (atreladas às centrais de controle). Na Figura 4 podemos verificar como as imagens-montagem foram construídas a fim de lançar ao espectador dois distintos sinais entre os gestos de montagem glitch-alike, ambos representativos dos dispositivos de vigilância e controle, que permearão todo o conceito do episódio. Trata-se, portanto, de outra referência (reverência) cultural: as antenas de TV remetem à abertura do filme sci-fi de Truffaut (1966) uma narrativa audiovisual síntese do argumento cinematográfico de Fahrenheit 451 (título homônimo do livro em que foi baseado, o romance distópico de Ray Bradbury, de 1953).

\section{Conclusão}

Meu ponto de vista é o da estética. [...] E sabido que Platão distinguia as artes uteis, que tomavam os processos da natureza po $r$ modelo, e a e la se adaptavam, para domina-la - em proveito do proprio homem -, e as inuteis - "Como a pintura e a musica". [...] Não esperem de mim tomar partido contra a maquina ou contra a técnica. Muito ao contrario, julgo que, frente a elas, os arquitetos e os artistas em geral, viram ampliar-se o seu repertorio formal assim como ampliaram seus meios de realizar. (Artigas 2015)

Mergulhar nos episódios de Black Mirror nos permite trabalhar a crítica dessa série, originalmente desenhada para uma rede de televisão, em diversas frentes. A começar pelo meio "televisivo" onde em que ela é atualmente disponibilizada (Netflix) e, a partir do qual, podemos operar em distintos dispositivos (computadores pessoais ou aparelhos celulares ou, ainda, conexões via Chromecast da Google, AppleTV , etc).

Esse "começar" aufere valor à vinheta de abertura da série. As vinhetas de abertura - opening title sequences - são comumente realizações audiovisuais esquecidas, senão negligenciadas, nos estudos acadêmicos de cinema e televisão. Ainda que de curtíssima duração, a sequência de abertura em Black Mirror induz a uma síntese sobre as questões perpetuadas episódio a episódio, como pudemos verificar aqui: o encontro da catarse com a desintegrac ao, a quebra, a ruptura; o rasgarse da caixa-preta, o enfrentamento do sublime.

As Pathosformeln - conceito apropriado desde experimentos de montagens estáticas intervalares do movimento operadas a um século atrás por Aby Warburg - nos ajudam a compreender os gestos que se 
repetem no âmbito das imagens de ficção científica que, por sua vez, são desencadeadas através de processos recognoiscíveis que se perpetuam na experiência estética.

Parafeaseando o professor Artigas em sua aula inaugural na Faculdade de Arquitetura e Urbanismo da USP (1967), alinhamo-nos entre os que estao convictos de que a maquina permite a arte uma func ao renovada complementar na sociedade. Esta foi, alias, a tese que tentamos experimentar aqui, aproveitando a oportunidade para tecer considerac oes em torno do projetar - to design - como base da composição audiovisual junto à noção de motion graphics - linguagem da arte e da tecnica - a partir da qual nos interessa elaborar ensaios críticos sobre tais gestos de montagem em Black Mirror. Assim, "design" - como palavra - traz consigo um conteudo sema ntico extraordinario e pode vir a ser uma das formas novas de pensamento - estado-da-arte da imagem em movimento - sobre as atividades artísticas na sociedade.

Interessa-nos, portanto, a estética (áudio-)visual contemporânea a partir da compreensão de uma construção (composição) através da hibridização pela qual têm passado as imagens em movimento nos últimos vinte e cinco anos (pelo meinimamenteos). As narrativas em Black Mirror ocorrem na lógica de imagens-montagens, da remixabilidade profunda do audiovisual digital.

Dessa maneira, a nível narrativo, Black Mirror é uma série televisiva de cunho moralizante-fabular, com duplo papel - entre o entretenimento e uma educação reflexiva -, que opera através de associações pósmodernistas de apropriação, collage e pastiche. Para além da associação aos efeitos visuais - comumente de caráter tecnicista (a partir de análises da utilização de chromakeychroma-key, etc., e outras técnicas pelo com as quaisl o software After Effects é muitas vezes identificado) -, a forma da dramaturgia em Black Mirror ocorre através de gestos de montagem particulares, como os motion graphics - "visuais projetados nao-narrativos e nao-figurativos que mudam ao longo do tempo" (Frantz 2003). Ou seja, ainda que os motion graphics estejam há muito associados a vinhetas ou audiovisuais publicitários, tal arte híbrida opera também em trabalhos desenvolvidos no âmbito das artes visuais ${ }^{19}$ assim como em potentes samples das estéticas do banco de dados (do live cinema às obras em dispositivos interativos).

Portanto, a utilização de motion graphics em Black Mirror apresenta tanto as mudanças ocorridas nos modus operandi da criação televisiva (e cinematográfica) como - e principalmente - a potência narrativa e dialógica oriunda desse tipo de composição audiovisual, quando a imagem em movimento - e seus gestos de montagem - se torna design, projeto, vencendo finalmente o conflito histórico entre a técnica e a arte.

\footnotetext{
${ }^{19}$ Manovich $(2013,105)$ exemplifica "for art-world", trabalhos de artistas como Jeremy Blake, Ann Lislegaard e Takeshi Murata.
} 


\section{BIBLIOGRAFIA}

Artigas, Vilanova. 2015 [1967]. "O Desenho". Centro de Estudos Brasileiros do Grêmio da FAU-USP. Acedido em 30 de Junho de 2018. https://issuu.com/itaucultural/docs/ocupacaoartigas aulaodese nho

Bellantfoni, Jeff \& Woolman, Matt. 2004. Type in Motion: Innovations in Digital Graphics. Londres: Thames \& Hudson.

Betancourt, Michael. 2013. The History of Motion Graphics: from AvantGarde to Industry in United States. Rockville: Wildside Press.

Braha, Yael \& Byrne, Bill. 2011. Creative Motion Graphic Titling. Oxford: Focal Press.

Burke, Edmund. 1998 [1757]. A Philosophical Enquiry into the Origins of the Sublime and Beautiful. Nova Iorque: Penguin.

Clayton, Alex \& Klevan, Andrew. 2011. The language and style of film criticism. Nova Iorque: Routledge.

Daney, Serge. 2007. A Rampa. São Paulo: Cosac Naify.

Debord, Guy. 1994 [1967]. A Sociedade do Espetáculo. Rio de Janeiro: Contraponto.

Deleuze, Gilles. 2007 [1990]. Post-Scriptum: Sobre as Sociedades de Controle. São Paulo: Ed34.

Diers, Michael; Girst, Thomas \& Moltke, Dorothea. 1995. "Warburg and the Warburgian Tradition of Cultural History". New German Critique 65 (Spring-Summer), 59-73.

Didi-Huberman, Georges. 2013 [1990]. Diante da Imagem. São Paulo: Ed34.

Dufour, Éric. 2011. O cinema de ficção científica. Lisboa: Colin.

Eisenstein, Sergei. 2002. O Sentido do Filme. Rio de Janeiro: Jorge Zahar. . 1988. The Psychology of Composition. Calcutá: Methuen Paperback. . 1983. "A montagem de atrações". In A experiência do cinema: antologia, org. Ismail Xavier. Rio de Janeiro: Graal-Embrafilme.

Flusser, Vilém. 2002 [1983]. Filosofia da Caixa Preta: Ensaios para uma Futura Filosofia da Fotografia. Rio de Janeiro: Relume Dumará.

Foucault, Michel. 2008 [2004/1978-79]. Nascimento da Biopolítica. São Paulo: Martins Fontes.

Frantz, Matt. 2014 [2003]. Changing over time: The Future of Motion Graphics. Dissertação de Mestrado. https://bit.ly/2CBYxKJ 
Freud, Sigmund. 2004 [1919/1925]. "The Uncanny" [translated by Alix Strachey, 1925]. In Fantastic Literature: a critical reader, ed. David Sandner, 74-101. Westport: Praeger Publishers.

Galloway, Alexander. 2009. "Debord's Nostalgic Algorithm”. Culture Machine. Culture Machine (vol 10), 131-156.

Ginzburg, Carlo. 2014. Medo, Reverência, Terror. São Paulo: Companhia das Letras. 1989. Mitos, Emblemas, Sinais. São Paulo: Companhia das Letras.

Hoffmann, Ernst Theodor Amadeus. 1993. Contos fantásticos: o vaso de ouro, os autômatos, o homem da areia. Rio de Janeiro: Imago.

Hume David. 2002. Ensaios morais, políticos e literários. Lisboa: Imprensa Nacional - Casa da Moeda.

Kant, Immanuel. 1998. Crítica da faculdade do juízo. Lisboa: Imprensa Nacional - Casa da Moeda.

Krasner, Jon. 2008. Motion Graphic Design: Applied History and Aesthetics. Oxford: Focal Press.

Manovich, Lev. 2013. Software Takes Command. Nova Iorque: Bloomsbury Academic. . 2007. "After Effects, or Velvet Revolution”. Artifact I (2), 67-75.

McLuhan, Marshall. 1969 [1964]. Os Meios de Comunicação como Extensões do Homem. São Paulo: Cultrix.

Meirelles, Fernando. 1991. "A Infância Consumida”. In Rede imaginária: televisão e democracia, org. Adauto Novaes, 263-267. São Paulo: Companhia das Letras \& Secretaria Municipal de Cultura.

Moradi, Irman. 2004. "GTLCH Aesthetics". Dissertação de Mestrado. School of Design Technology (Department of Architecture). The University of Huddersfield.

Opolski, Debora. 2017. Introdução ao Desenho de Som. Rio de Janeiro: Tratore.

Plunkett, John. 2016. "Channel 4 has lost the right to show Charlie Brooker's Black Mirror in the UK six months after the acclaimed drama was snapped up by Netflix in a reported $\$ 40 \mathrm{~m}$ deal." Acedido em 30 de dezembro de 2018. https://www.theguardian.com/media/2016/mar/29/netflixchannel-4-charlie-brooker-black-mirror

Robinson, Lonna. 2000. Typography in film. Tese de Doutoramento. Rochester Institute of Technology.

Spinoza, Baruch. 2008. Ética. Belo Horizonte: Autêntica Editora.

Szafir, Milena. 2018. Las formas videográficas en la Sociedad del Espectáculo. Proceedings XVII Festival Internacional de La Imagen 
(XV Foro Académico de Arte y Diseño Latinoamericano). Manizales: Universidad de Caldas.

. 2018b. "Composic ao: Ensaio em 03 Movimentos". OuvirOUver (v.14, n.2), 340-360.

2017. Design \& tele-audiovisualidades (ou, das formas videográficas). Anais $40^{\circ}$ Congresso Brasileiro de Ciências da Comunicação. Curitiba: UTP.

. 2017 [2016]. Stream'Engrams @ Audio-Visual Design'ing \#17. Catalogue ISEA2017 (XIV Academic Forum Latin American Art and Design). https://issuu.com/imagenfest/docs/__ catalogo

. 2016. M-Lab: \#MESA v.2. Anais 39 Congresso Brasileiro de Ciências da Comunicação. São Paulo: USP.

. 2016. Projet'ares Audiovisuais v.5 - montagem, sci-fi \& motion graphics. Anais Digitais XX SOCINE. Curitiba: UTP.

- 2015. Retóricas Audiovisuais 2.1 - Ensino e Aprendizagem Compartilhada: Passado, Presente, Futuro (ou Por uma ArqueologiaCartografia da Montagem). Tese de Doutoramento. Escola de Comunicação e Artes. Universidade de São Paulo (USP).

. 2015 [2014]. "Montagens audiovisuais extra-apropriac ao: por uma pedagogia do filme-ensaio na cultura digital”. In $A$ Sobrevivê ncia das Imagens, org. Alessandra Brandão et.al. Campinas: Papirus.

. 2010. Retóricas Audiovisuais (e o filme Tropa de Elite na cultura em rede). Dissertação de Mestrado. Escola de Comunicação e Artes. Universidade de São Paulo (USP).

. 2009 [2008]. Retóricas Audiovisuais em Rede: Debord para além de sua Distopia - breve análise de A Sociedade do Espetáculo, o filme (1973).

http://stoa.usp.br/surveillanceme/files/1722/9488/Exame+de+ Quali_txt02-correcao01.pdf . 2006 [2004]. "Work in Progress: Performance-Vj'ing-Wireless de Performances Panopticadas a Cyborg Panopticando/ Manifesto21 - ou a elaborac ao de um manifesto multimidiatico, o Manifesto Panoptico". In net cultura 1.0/ Digitofagia, org Giseli Vasconcelos et. al. Sao Paulo: Radicais Livros. 


\section{FILMOGRAFIA}

3\%. Prod. exec. Pedro Aguilera. Netflix, Brasil, 2016-2018.

Blade Runner. Realizado por Ridley Scott. The Ladd Company \& Shaw Brothers. Warner Bros. EUA, 1982, 117 min.

Black Mirror. Prod. exec. Charlie Brooker. Netflix, Reino Unido, 20112018.

Minority Report. Realizado por Steven Spielberg. DreamWorks et. al., Twentieth Century Fox. EUA, 2002, 145 min.

Tha Affair. Prod. exec. Hagai Levi \& Sarah Treem. Netflix, EUA, 20142018.

The Dark Crystal. Realizado por Jim Henson \& Frank Oz. ITC Entertainment \& Henson Organisation Ltd. Universal Pictures, EUA, 1982, 93 min.

The Film Before The Film. Realizado por Daniel Wangen \& Christian Mahler. Berliner Technische Kunsthochschule. Alemanha, 2013, $12 \mathrm{~min}$. 